\title{
Paralytic Peptide Binding Protein (PP-BP) Gene Expression During Egg Diapause and Its Multi-Gene Organization in the Silkworm Bombyx mori.
}

\author{
Sasibhushan Sirigineedi, Geetha N Murthy, Guruprasada Rao and, Kangayam M Ponnuvel* \\ Genomics Division, Seribiotech Research Laboratory, Carmelaram Post, Kodathi, Bangalore 560 035, India
}

\section{Abstract}

Paralytic peptide binding proteins (PP-BP) are 30KP proteins that show similarity to ENF binding proteins. The ENF-BP act as active regulators of ENF peptides. ENF peptides are multifunctional insect cytokines. The comparison of gene expression in diapause induced and non-diapause eggs at different time intervals after oviposition showed an upregulation of PP at $18 \mathrm{~h}$ as well as PP-BP at 12 and $18 \mathrm{~h}$ after oviposition along with few other genes. The current study has been taken up to investigate the role of PP as well as PP-BP in diapause induction in polyvoltine silkworms and to study the multigene organization of PP-BP in the Bombyx mori genome. The tissue specific expression analysis revealed that, PP-BP is highly expressed in fat body followed by egg and brain while no expression was observed in midgut. The expression levels of PP and PP-BP in diapause and non-diapause eggs from Oh to 48h after oviposition, validated through realtime PCR revealed that PP is highly expressed at 18 and 24h while PP-BP expression is higher at 12 and 18h time intervals suggesting their possible role in diapause induction. The whole genome survey of the PP-BP paralogous sequences revealed a total of $46 \mathrm{~B}$. mori PP-BP homologs that are classified into 3 categories viz., ENF-BP, Typical 30KPs and serine/threonine rich 30KPs. These paralogous sequences are distributed on chromosomes 7, 20, 22 and 24, all 30KP and S/T rich 30KP proteins are present in the same locus of chromosome 20.

\section{Keywords:}

Paralytic peptide Binding (c) 2013 The Korean Society of Sericultural Sciences

Int. J. Indust. Entomol. 26(1), 31-40 (2013) protein, Multi-gene family, B. mori, Egg diapause

\section{Introduction}

During insect development the central nervous system regulates growth, metamorphosis, diapause and reproduction by secreting peptides. Insect hemolymph contains various proteinaceous components viz., transport proteins, storage proteins, peptide hormones which are essential for growth and development, and defensive peptides while induced by bacterial invasion or injury. Injection of the hemolymph obtained from larvae of other Manduca species into that of Manduca sexta, the latter become paralyzed. This fac-

\section{*Corresponding author.}

Dr. K.M.Ponnuvel

Genomics Division, Seribiotech Research Laboratory, Carmelaram Post, Kodathi, Bangalore 560 035, India

Tel: +91-80-28440651 / FAX: +91-80-284401901

E-mail:kmpvel@yahoo.com

http://dx.doi.org/10.7852/ijie.2013.26.1.031

(C) 2013 The Korean Society of Sericultural Sciences 
tor from the hemolymph was isolated from several kinds of lepidopteran hemolymph and characterized as 23 amino acid peptides which were named as Paralytic peptide (Ha et al., 1999).

This ENF peptide family shares similar amino acid sequence and conserved at $\mathrm{C}$-terminal region. It is named after the $\mathrm{N}$-terminal-conserved three amino acids (Glu-Asn-Phe) (Strand et al., 2000). ENF family proteins are synthesized as inactive precursors that are activated by a serine protease cleavage. Mature ENF family proteins, including Bombyx mori paralytic peptide (BmPP), have been reported to show multiple effects, such as induction of morphological changes of plasmatocytes, inhibition of larval growth, promotion of cell growth and local muscle contraction $(\mathrm{Ha}$ et al., 1999; Sasagawa et al., 2001; Miura et al., 2002; Nakahara et al., 2003).

In B. mori the embryonic diapause is normally induced by the diapause hormone (Bommo-DH), which is produced in the pupae from the suboesophageal ganglion. Injection of Antheraea yamamai-paralytic peptide (Antya-ParP) into non-diapausing pupae of B. mori, however, converted the pupae into diapauses egg producers. Even extirpation of brain along with SG had no influence on the induction of diapausing egg production by Antya- ParP, which demonstrated that Antya- ParP does not act via endogenous B. mori diapause hormone (Bommo-DH) but mimics its action at the level of target tissues. No homology exists between the primary sequences of the Bommo-DH and ENF peptide families, but this does not exclude that one can mimic the action of the other (An et al., 2007).

In B. mori , 30K proteins are synthesized by the fat body and then secreted into hemolymph during the last instar larval stage, where they get accumulated to a high concentration and then are gradually absorbed into the oocyte (Chen and Yamashita, 1990). About $35 \%$ of the total yolk proteins consists of $30 \mathrm{~K}$ proteins (Zhu et al., 1986). These proteins have a variety of biological functions, providing a source of nutrients for embryogenesis (Zhong et al., 2005), binding to glucan to defend fungal infection (Ujita et al., 2002;
2005) and inhibiting apoptosis (Kim et al., 2003; Park et al., 2003).

There are several 30KPs as well as their homologs reported in silkworm B. mori. Ten 30KP genes have been identified in the silkworm (Sun et al., 2007), and more genes show sequence homologous to 30KPs like B. mori larvae serum protein (LSP) and LSP$\mathrm{T}$ protein that are homologs of 30KPs (Fujiwara and Yamashita, 1992; Miyagawa et al., 2004). Microvitellogenin of Manduca sexta and the C terminus (170th430th amino acids) of growth- blocking peptide binding protein (GBP-BP) of Pseudaletia separata also show some similarity to 30KPs (Matsumoto et al., 2003; Wang et al., 1989). Both Growth blocking peptide (GBP) and PP belong to ENF peptide family in view of the consensus N-terminal sequence (Glu-AsnPhe). A cytokine-like factor, B. mori paralytic peptide (BmPP), which was purified from the silkworm hemolymph, belongs to the ENF peptide family. Like other Paralytic peptides, the Paralytic peptide of $B$. mori (BmPP) is also multifunctional ENF-peptide (Ha et al., 1999). The C-terminal amino acid sequence (190th-430th amino acids) of B. mori paralytic peptide binding proteins is homologous to 30KPs ( $\mathrm{Hu}$ et al., 2006). Growth-blocking peptide binding protein was reported to function for silencing the GBP action (Matsumoto et al., 2003)

In a recent study by Zhang et al., (2012), 73 genes of Lipoprotein_11 family were retrieved from 12 lepidopteran species and the structural analysis showed that these genes could be divided into three distinct subfamilies according to their differential $\mathrm{N}$-terminal domain. A novel subfamily of Lipoprotein_11 was reported for the first time in the study and named serine/threonine-rich 30KP according to its exclusive domain.

The abundant level of 30KPs expression suggests that they may serve as storage proteins (Fujiwara and Yamashita, 1992; Izumi et al., 1981; Wang et al., 1989). Not much is known about the molecular mechanisms controlling the terminal process in the cellular immune response. The expression of PP and PP-BP has not been studied till date in diapause induced eggs 
of multivoltine silkworm $B$. mori.

In this study we report a high expression of the paralytic peptide and paralytic peptide binding protein in the diapause induced eggs of multivoltine silkworm B. mori which may suggest that these proteins might also play a role in regulation of diapause induction.

\section{Materials and Methods}

\section{Insect rearing}

The multivoltine strain MW13 (Indian origin) was selected for the study. The larvae were reared as per the standard rearing method of Krishnaswami., (1978) up to last instar to obtain non-diapausing eggs, The late stage (4th \& 5th instars) larvae were then reared under low temperature $\left(18^{\circ} \mathrm{C}\right)$ and photoperiod $(6 \mathrm{~L}$ : 18D) up to cocooning stage and the moths were made to lay diapausing eggs at normal room temperature $\left(25^{\circ} \mathrm{C}\right)$ (Saravanakumar et al., 2008).

\section{RNA isolation}

After oviposition, the diapause and non-diapause egg samples were collected from 0 to $48 \mathrm{~h}$ at every $6 \mathrm{~h}$ time interval, while, other tissues were collected from the day 3 of $5^{\text {th }}$ instar larvae. Total RNA was extracted from the diapause and non-diapause eggs using TRIzol reagent (Invitrogen, USA), denatured in formaldehyde, formamide and electrophoresed in $2.0 \%$ agarose gels.

\section{cDNA preparation}

The first strand cDNA was synthesized utilizing RNA $(2 \mu \mathrm{g})$ treated with $0.5 \mu \mathrm{l}$ of DNase buffer and $0.5 \mu \mathrm{l}$ of DNase (Invitrogen, USA) for 15 minutes. Then, the reaction was terminated by heating at $75^{\circ} \mathrm{C}$ for 10 minutes, to the above DNase treated sample, $1 \mu 110 \mathrm{mM}$ dNTP, $1 \mu$ l oligo (dT)18 (0.01mM) (Eurofin India Pvt Ltd, Bangalore) was added followed by incubation at $65^{\circ} \mathrm{C}$ for 5 min. Finally $1 \mathrm{X}$ reverse transcriptase buffer $(4 \mu \mathrm{l}), 5 \mathrm{mM}$ DTT $(1 \mu \mathrm{l})$ and $1 \mu \mathrm{l}$ of M-MLV Superscript III reverse transcriptase (Invitrogen, USA) was added to obtain a final volume of $20 \mu \mathrm{l}$. The reaction was terminated by heating at $75^{\circ} \mathrm{C}$ for $10 \mathrm{~min}$ according to the manufacturer's protocol.

\section{Microarray experiment and data analysis}

A genome wide oligonucleotide microarray containing 24,924 probes were used to investigate the gene expression profiles of diapause induced and nondiapause eggs of multivoltine silkworm $B$. mori at 18 and $30 \mathrm{hrs}$ after oviposition. The complete sets of raw and normalized data from this study have been deposited in the NCBI Gene Expression Omnibus (GEO) repository (accession number GSE35622).

\section{Reverse transcription polymerase chain reaction (RT PCR) analysis for tissue specific gene expression}

PCR amplification was performed in a $25 \mu \mathrm{l}$ reaction mixture containing $2.0 \mu \mathrm{l}$ of $10 \mathrm{X}$ reaction buffer (100 mM Tris-HCL, pH 8.3, $500 \mathrm{mM} \mathrm{KCl),} 0.2 \mathrm{mM}$ dNTPs, $1.5 \mathrm{mM} \mathrm{MgCl}_{2}, 10$ picomoles of forward and reverse primers, $0.3 \mathrm{U}$ of Taq DNA polymerase (MBI Fermentas) with $1 \mu \mathrm{l}$ first strand cDNA as template. $\beta$ actin (FP 5'cactgaggctccctgaac 3' and RP 5' ggagtgcgtatccctcgtag 3') (Eurofins, Bangalore) was used as an internal standard. The PCR amplification was carried out under the following conditions: $94^{\circ} \mathrm{C}$ for $3 \mathrm{~min}$ followed by 27 cycles of $94^{\circ} \mathrm{C}$ for $30 \mathrm{~s}$, $54^{\circ} \mathrm{C}$ for $30 \mathrm{~s}, 72^{\circ} \mathrm{C}$ for $2 \mathrm{~min}$ and a final extension of $7 \mathrm{~min}$ at $72^{\circ} \mathrm{C}$.

\section{Real time PCR analysis}

One $\mu \mathrm{l}$ of first strand cDNA synthesized from diapause and non-diapause eggs from 6 to $48 \mathrm{~h}$ after oviposition was used as template for qPCR analysis in a $25 \mu 1$ reaction mixture containing SYBR green mas- 
Paralytic peptide binding protein
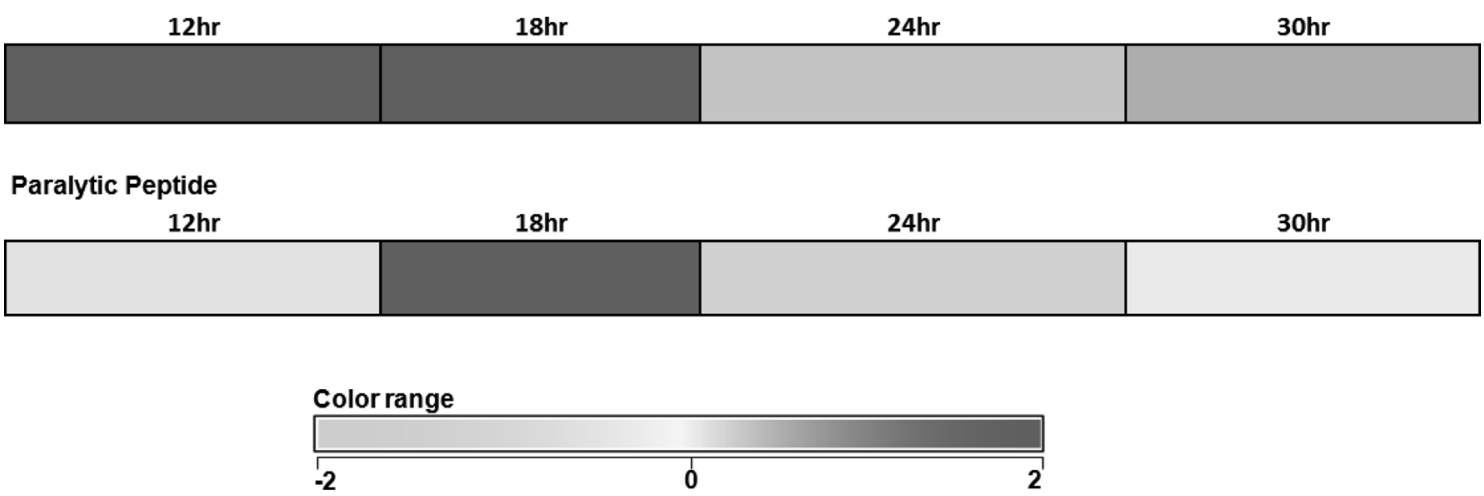

Fig. 1. Microarray expression profile of paralytic peptide and paralytic peptide binding protein in diapause induced eggs of silkworm B.mori at different time intervals. Fold change gene expression values are provided as log base 2 . The fold change considered for upregulation was $>=0.8$ and for down regulation was $<=-0.8$.

termix (ABI, CA, USA) and the specific primers designed for Realtime PCR (qPCR). The reactions were conducted on a STRATAGENE Mx 3005P realtime PCR system. The experiment was performed in triplicate and results were standardized to the expression level of the constitutive $\beta$ actin gene. A Non-template control (NTC) sample was also run to detect contamination if any.

\section{Identification of paralogous gene sequences in B.mori}

The B.mori cDNA sequences were BLAST searched with Silkworm Genome Database (http:// silkowrm.genomics.org.cn) to identify paralogous multigene family. Using the silkworm database, the functional annotation of genes, paralogous gene sequences, gene products and chromosome mapping were determined. Further, the tools provided in the database were utilized to perform specific genomic BLAST search as well as Map view (a visualization tool that provides a graphical view of selected genes). The organization of paralogous 30KP multigene family on individual scaffold was also analyzed using BLAST search with Gene ID. Phylogenetic analyses were performed with the multiple sequence alignment using ClustalW through MEGA 4 (Kumar et al., 2004). The Bootstrap consensus NJ tree for
30KP paralogous gene sequences was constructed with the Bootstrap values. Signal peptide cleavage sites were predicted using SignalIP algorithm (www. cbs.dtu.dk/services/SignalIP), based on the Neural Network and Hidden Markov Model.

\section{Results}

Oligonucleotide microarrays containing 24,924 probes were used to investigate the gene expression profiles of diapause induced and non-diapause eggs of multivoltine silkworm B.mori at 18 and 30hrs after oviposition. The complete sets of raw and normalized data from this study have been deposited in the NCBI Gene Expression Omnibus (GEO) repository (accession number GSE35622).

A total of 638 genes were upregulated and 1136 genes were down regulated at $18 \mathrm{~h}$ after oviposition, whereas, 675 genes were found to be upregulated and 595 genes down regulated at $30 \mathrm{~h}$ after oviposition. Further, genes whose expression was detected in diapause induced and non-diapause silkworm eggs were classified into two groups, stably expressed and variably expressed genes at both 18 and $30 \mathrm{~h} .115$ genes were stably upregulated, while 117 genes stably down regulated at both 18 as well as $30 \mathrm{~h}$. Up and down regulated genes showing fold change of 0.8 and 

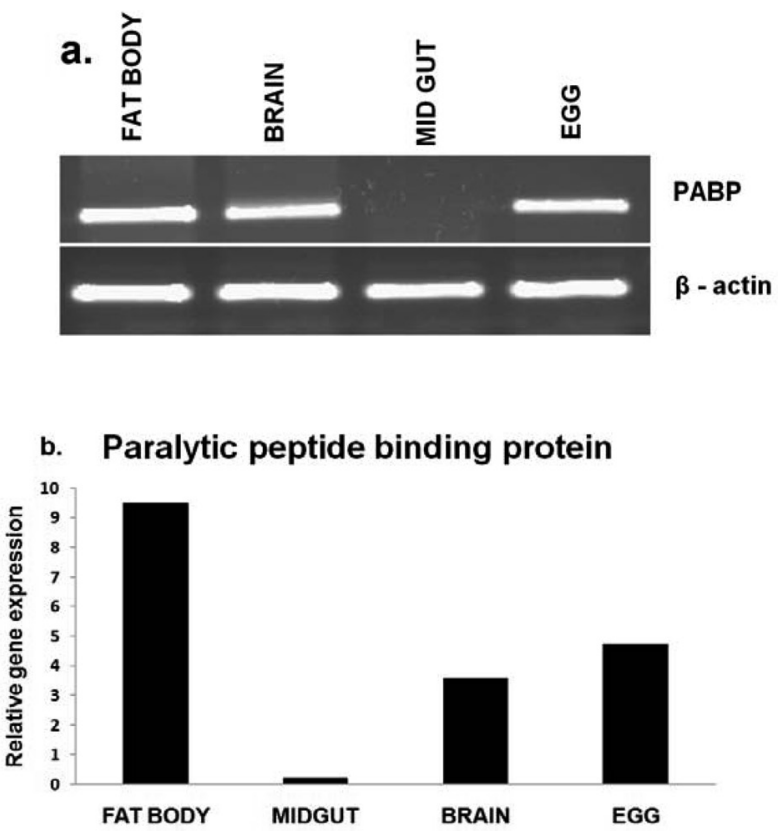

Fig. 2. Expression profiles of paralytic peptide binding protein in different tissues. B.mori using (a) semi quantitative RT-PCR and (b) real time PCR (qPCR), $\beta$-actin was used as internal control.

above were considered as significantly expressed. 315 genes were found to be variably upregulated at $18 \mathrm{~h}$ and 259 genes were found to be variably up regulated during $30 \mathrm{~h}$ of diapause-induced eggs (Unpublished data). Among those upregulated genes PP and PP$\mathrm{BP}$ were significantly up-regulated at 12 and 18 hours (Fig. 1). Further these two gene expressions were analyzed in diapause induced eggs at different time intervals after oviposition.

\section{PP-BP gene expression in different tissues}

RT-PCR analysis was performed to determine the tissue specific expression of the $B$. mori PP-BP gene. Different tissues viz., fat body, brain, mid gut of $5^{\text {th }}$ instar $3^{\text {rd }}$ day larvae as well as, diapause induced eggs were analyzed for tissue distribution of PP-BP transcripts. The results indicated that PP-BP was highly expressed in fat body followed by brain and eggs, while no expression was observed in mid gut tissue (Fig. 2. a). B. mori $\beta$-actin gene was used as an inter-
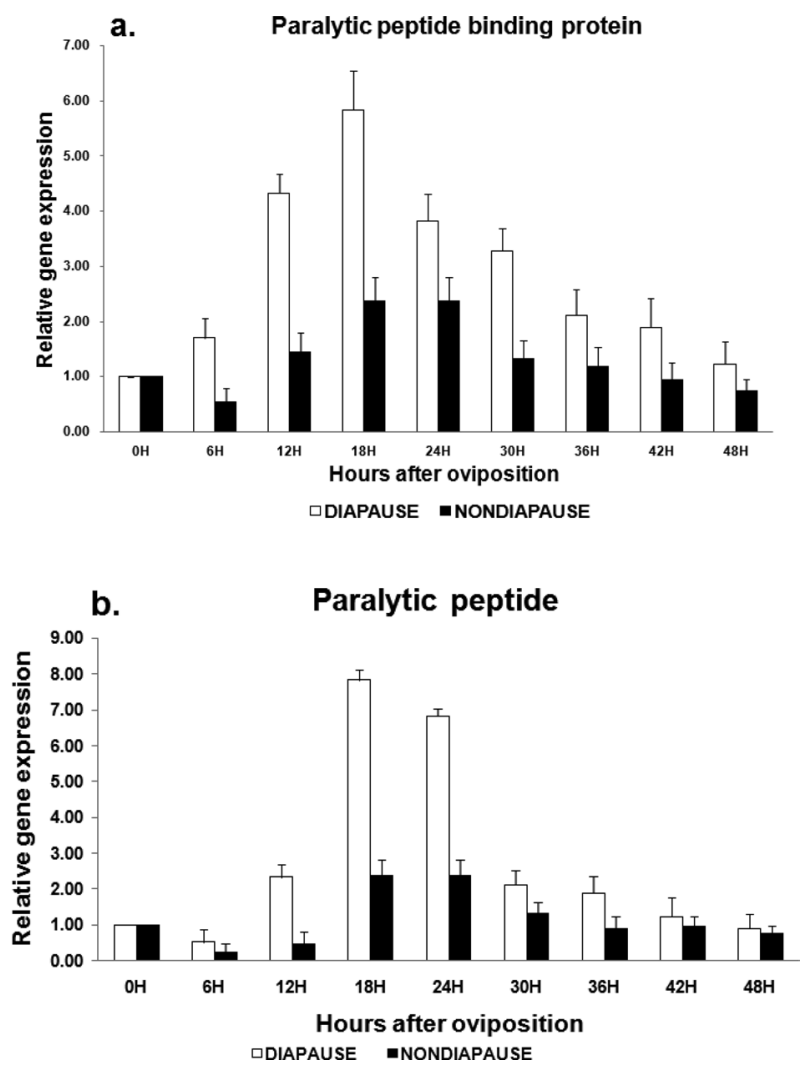

Fig. 3. Relative gene expression patterns of (a) paralytic peptide binding protein gene and (b) paralytic peptide gene upregulated during diapause.

nal control. Further the results validated through realtime PCR analysis (Fig. 2. b) revealed that the PP-BP gene expression was higher in diapause induced eggs, compared to the non-diapause eggs.

\section{Differential expression of B. mori PP-BP and $\mathrm{PP}$ in diapause induced eggs}

The expression level of PP-BP gradually increased from 0 to $24 \mathrm{~h}$, where, the expression was at maximum, followed by a very steep decrease from 30 to $48 \mathrm{~h}$ in diapause induced eggs. The gene expression in non-diapause eggs was very low from 6 to $48 \mathrm{~h}$ time intervals compared to diapause eggs. The expression level of paralytic peptide was almost similar to PP-BP in diapause eggs while in non-diapause eggs they were slightly higher compared to PP-BP. (Fig. 3a, 3b). 

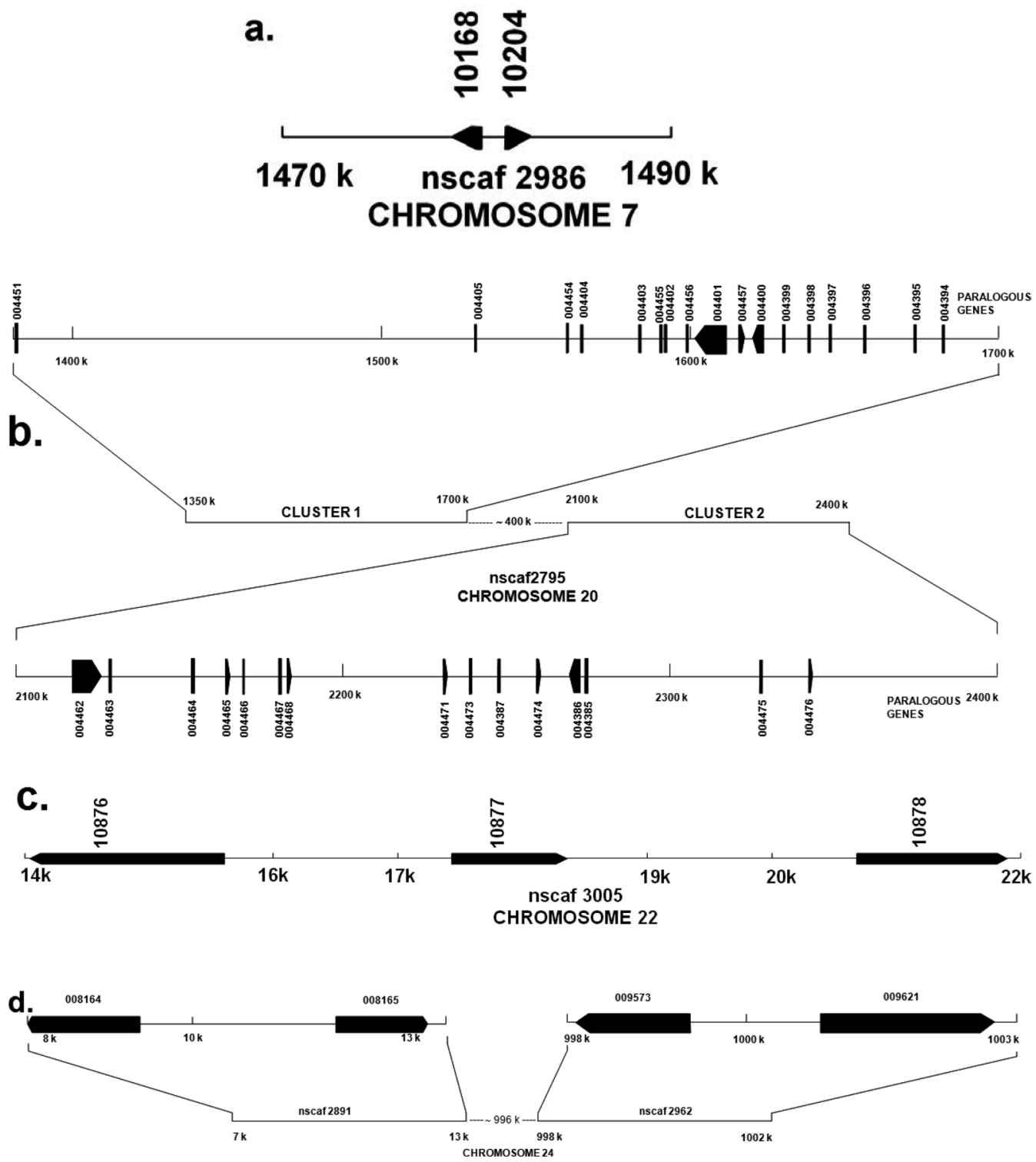

Fig. 4. Schematic representation of gene clusters arranged on different chromosomes of B. mori. (a) The two paralogous genes of ENF-BP located in nscaf 2986 between $1470 \mathrm{~kb}$ and $1490 \mathrm{~kb}$ on chromosome 7. (b) The two major gene clusters of $30 \mathrm{KP}$ and $\mathrm{S} / \mathrm{T}$ rich $30 \mathrm{KP}$ located in nscaf 2795 . Cluster one flanked from $1350 \mathrm{~kb}$ to $1700 \mathrm{~kb}$ and cluster two from $2100 \mathrm{~kb}$ to $2400 \mathrm{~kb}$ on chromosome 20 with intergenic region of $400 \mathrm{~kb}$. (c) Three paralogous genes of ENF-BP gene located in nscaf 3005 between $14000 \mathrm{~kb}$ to $22000 \mathrm{~kb}$ on chromosome 22. (d) Two clusters of ENF-BP gene located in nscaf 2891 and nscaf 2962. Cluster one flanked from $1350 \mathrm{~kb}$ to $1700 \mathrm{~kb}$ and cluster two from $2100 \mathrm{~kb}$ to $2400 \mathrm{~kb}$ on chromosome 24 with intergenic region of $996 \mathrm{~kb}$.

Genomic organization of B. mori PP-BP paralogous genes

The cDNA sequence of $B$. mori PABP was subjected to blast analysis and several paralogous contigs were identified. A total of 46 paralogous sequences were identified which were distributed on chromosomes 7 , 20, 22 and 24 (Fig. 4. a, b, c, d). Based on the structural characteristics of the above identified 46 sequences they have been classified into ENF-BP, typical 30KP, and 


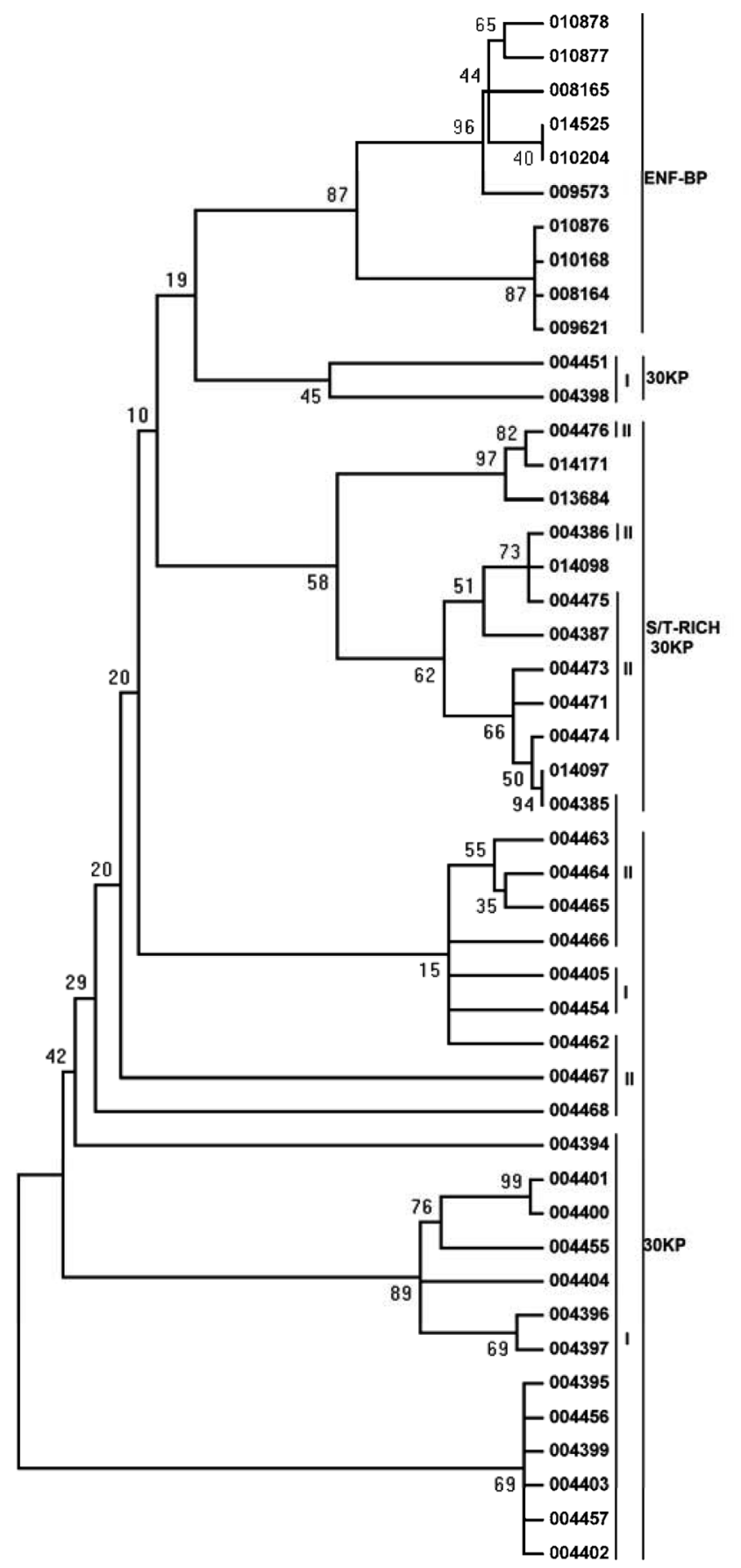

$\begin{array}{ccccccccc}1 & 1 & 1 & 1 & 1 & 1 & 1 & 1 & 1 \\ 0.8 & 0.7 & 0.6 & 0.5 & 0.4 & 0.3 & 0.2 & 0.1 & 0.0\end{array}$

Fig. 5. Neighbor-joining tree of paralogous genes of paralytic peptide binding protein, percentage of bootstrap values (based on the 1000 replication) for the main branching nodes are shown on the tree. The paralogous gene sequences retrieved from silkworm genome database are indicated by Gene ID number. serine/threonine-rich $30 \mathrm{KP}$. ClustalW analyses were performed with the multiple sequence alignment using ClustalW through MEGA 4 which revealed that these paralogous sequences formed three major clusters. Of the 46 sequences identified, 10 fall under the category of ENF-BP cluster, 12 fall under S/T-rich $30 \mathrm{KP}$ cluster and 24 of them fall under typical 30KPs clusters (Fig. 5).

\section{Discussion}

Since the finding of the first member of the ENF peptide family, eleven lepidopteran species including $B$. mori have been found to have such peptides (Ha et al., 1999). Antya-ParP when injected in to the non-diapause egg producing pupae, the pupae are converted into diapause egg producers even lacking sub esophageal ganglion. Even though Bommo-DH and ENF peptides share no homology in the primary sequences, the later can mimic the action of the former. ENF peptides are regarded as insect cytokines and have multiple biological activities, including mitogenic, paralytic, hemocyte-spreading, and growth blocking activities (Aizawa et al., 2002; Kamimura et $a l ., 2001)$. However, limited information is available on diapause eggs

In the present study, the gene expression levels of PP and PP-BP were compared in diapause and nondiapause eggs after oviposition. The expression of PP was higher at $18 \mathrm{~h}$ similarly the expression of both PP and PP-BP genes was higher at 12 and $18 \mathrm{~h}$ along with few other genes in microarray experiment. These genes were taken up for further study, which were validated through q-PCR.

Most of the reports emphasize the role of ENF peptides in cellular immunity and cell proliferation. An et al., (2007) proved that Antherea yamamai paralytic peptide induces egg diapause even in pupae where subesophageal ganglion had been extirpated and also causes a rapid and rigid larval paralysis in B. mori. It was also inferred that AnyParP interacts with other pathways to excite diapause rather than those involved in paralysis. It was also speculated that AnyParp and 
homologs act on the same channel in the cascade of diapause egg induction as the $\mathrm{DH}$.

The structural and phylogenetic analyses of paralogous sequences revealed that these sequences can be categorized into three categories ENF-BP, typical 30k proteins and $\mathrm{S} / \mathrm{T}$ rich $30 \mathrm{~K}$ proteins. The $30 \mathrm{k}$ proteins are involved in the diapause mechanism through regulating the action of paralytic peptide.

In a study by Zhang et al., (2012), the ENF-BP genes were also expressed in the gonads (ovary and testis), fat body, head, integument, silk gland, etc which was different from the hemocyte specific expression pattern of $P$. separate ENF-BP. The Bm ENF peptides, also show extensive tissue expression profiles, such as in gonads, fatbody, integument, central nervous system, etc. (Aizawa et al., 2002; Kamimura et al., 2001). Similarly in the present study it is found that the PP-BP is highly expressed in fat body followed by eggs and brain while, no expression is observed in midgut. As ENF peptides are reported to play a role in regulation of the cell proliferation as growth factors, it can also be assumed that ENF-BPs may be involved in development by regulating the expression or activities of ENF peptides.

\section{Multigene organization of B. mori PP-BP gene}

Genes that have originated by gene duplication retained a certain degree of similarity forming multigene families. The multigene family members are often arranged in a compact cluster due to chromosomal rearrangements subsequent to gene duplications. The members of a multigene family can be functional or nonfunctional which are known as pseudo genes. Multigene families containing paralogous gene sequence that evolve in different ways, and assumption of the multigene family evolution is essential for estimation of its phylogeny. It is assumed that members of a multigene family may evolve at a faster rate and such members are designated as fast evolving genes. This phenomenon takes place when one gene member of a multigene family takes on a novel function, which is essential for survival and thus encounters significantly different selective pressure from other multigene family members. Another usual assumption of molecular tree of multigene family is that, each branch of the tree evolves independently from other branches. These families often show coincidental evolution, either indirectly through biased mutational and selective force or directly by mechanism such as gene conversion (Roach et al., 2005).

A total of forty six B. mori paralytic peptide binding protein homologs were retrieved from the silkoworm genome database (http://silkowrm.genomics.org.cn). These forty six paralogous gene sequences, belonging to PP-BP gene family diverged into three different groups, viz., ENF-BP, S/T rich, Typical 30KP. Ten sequences belonged to ENF-BP, twelve to $\mathrm{S} / \mathrm{T}$ rich $30 \mathrm{KP}$ proteins and Twenty four to typical 30KPs. The PP-BP has conserved domain similar to ENF-BP and hence, ENF-BP is also considered as paralytic peptide binding protein. The twenty four $30 \mathrm{KP}$ paralogous genes are organized in a single locus of chromosome 20; however, two paralogous genes of 30KPs formed a separate cluster from the remaining $30 \mathrm{KP}$ gene family (Fig. 5). The 30KPs can be divided into 2 groups one as typical $30 \mathrm{KP}$ and $\mathrm{S} / \mathrm{T}$ rich $30 \mathrm{KP}$. The $\mathrm{S} / \mathrm{T}$ rich rich 30KP have a serine/threonine rich domain between signal peptides and N-terminal domain, while the $\mathrm{N}$ terminal of typical 30KPs is composed of the signal peptides and an un-conserved region. Twenty four 30KPs as well as Twelve $\mathrm{S} / \mathrm{T}$ rich $30 \mathrm{KPs}$ formed a major cluster located in nscaf 2795 of chromosome 20 (Fig. 4B). This locus was grouped into two clusters with intergenic region of $400 \mathrm{~K}$. The cluster 1 consists exclusively of $30 \mathrm{KP}$; however, the cluster 2 consists both $30 \mathrm{KP}$ and $\mathrm{S} / \mathrm{T}$ rich $30 \mathrm{KP}$. Though a major cluster is formed, the $30 \mathrm{KP}$ and $\mathrm{S} / \mathrm{T}$ rich $30 \mathrm{KP}$ grouped independently in this major cluster. The paralgous gene 04451 was located approximately $150 \mathrm{~kb}$ from the remaining cluster, indicating, that this paralogous gene has diverged from the single ancestral gene prior to multigene family formation, to further support this hypothesis the gene 4451 formed a separate cluster in the phylogenetic tree. Comparison of the molecular distance of the paralogous genes within the species indicates the amount of coincidental evolution (Walsh 
et al., 1995). The presence of $\mathrm{S} / \mathrm{T}$ rich subgroup in the $30 \mathrm{KP}$ group indicates that both the groups have evolved recently from the ancestral gene. The original gene might have originated from the common ancestors by gene duplication and later the individuals within the multigene family were formed during the process of evolution. Unlike the typical 30KP and ST rich 30KPs the multigene cluster of ENF-BP was spread over different chromosomes viz., chromosome number 7, 22 and 24. The long intergenic regions between two paralogous gene sequences as well as presence of these genes in different chromosomes indicate that the multi gene family evolved much ahead of typical $30 \mathrm{KP}$ and $\mathrm{S} / \mathrm{T}$ rich $30 \mathrm{KPs}$.

Similar phenomenon was observed for cecropin multigene family in B. mori. Cecropin B locus on genomic DNA consists of 6 paralogous gene groups as well as Cecropin D and E (Ponnuvel et al., 2010). However, the maximum intergenic region of $23 \mathrm{~Kb}$ was observed between Cecropin D and remaining Cecropin B family indicates that the two gene families were distantly evolved. The ENF-BP located on chromosome 24 had 4 paralogous gene sequences in a single locus of opposite orientation. These 4 genes of ENF-BP located on the same position of nscaf 3005 on chromosome 22 indicates that these 3 genes were closely evolved. Similarly, 2 genes present in nscaf 2986 of chromosome 27 also formed a subcluster from the remaining group. It was considered as $30 \mathrm{KPs}$ only based on the conserved sequence present in the $\mathrm{c}$ terminal region of the protein.

In the current study it is observed that paralytic peptide is specifically up-regulated at $18 \mathrm{~h}$ time point suggesting its possible role in induction of diapause along with other factors that contribute to the same. Excessive amount of PPs cause serious damage to insect self organization. Paralytic peptide binding proteins are also up-regulated during the diapause period, which suggests that PP-BP act as active regulators of the paralytic peptide (Matsumoto et al., 2003), as even the over expression of the paralytic peptide might cause damage to the cells.

Paralytic peptide and paralytic peptide binding protein interaction has to be further exploited to find out whether it is an alternative mechanism of diapause in- duction and also its possibility to design novel growth regulators in other insects.

\section{Acknowledgements}

This research work was supported by grants from Department of Biotechnology, Ministry of Science and Technology, Government of India (BT/PR11397/ PBD/19/192/2008 dated 30th June 2009).

\section{References}

Aizawa TY, Hayakawa K, Nitta K, Kawano K (2002) Structure and activity of insect cytokine GBP which stimulates the EGF receptor. Mol Cells 31, 1-8.

An YT, Yamashita A, Seino K, Imai K, Suzuki K (2007) Functional Mimicry of the Silkworm Diapause Hormone by an Insect Paralytic Peptide. J Insect Biotechnol Sericology 76, 51-55.

Chen YL, Yamashita O (1990) Nonselective uptake of different $30 \mathrm{kDa}$ plasma proteins by developing ovaries of the silkworm, Bombyx mori. J Seric Sci Jpn 59, 202209.

Fujiwara Y, Yamashita O (1992) Gene structure of Bombyx mori larval serum protein (BmLSP). Insect Mol Biol 1, 63-69.

Ha S, Suzuki A, Nagata S, Tanaka M, Kataoka H (1999) Structure determination and cDNA cloning of paralytic peptide in Bombyx mori, pp. 460-461, in Y. Shimonishi (ed.). Peptide Science - Present and Future. Kluwer Academic Publishers, Great Britain.

Hu ZG, Chen KP, Yao Q, Gao GT, Xu JP, Chen HQ (2006)

Cloning and characterization of Bombyx mori PP-BP a gene induced by viral infection. Biochem Biophys Acta 33, 975-983.

Izumi S, Fujie J, Yamada S, Tomino S (1981) Molecular properties and biosynthesis of major plasma proteins in Bombyx mori. Biochem Biophys Acta 660, 222-229.

Kamimura M, Nakahara Y, Kanamori Y, Tsuzuki S, Hayakawa Y, Kiuchi M (2001) Molecular cloning of silkworm paralytic peptide and its developmental 
regulation. Biochem Biophys Res Commun 286, 67-73

Kim EJ, Park HJ, Park TH (2003) Inhibition of apoptosis by recombinant $30 \mathrm{~K}$ protein originating from silkworm hemolymph. Biochem Biophys Res Commun. 308, 523528.

Krishnaswami S (1978) New technology of silkworm rearing, pp. 1-23, in Bulletin No. 2. Central Sericultural Research and Training Institute, Mysore, Central Silk Board, Govt. of India.

Kumar S, Tamura K, Nei M (2004) MEGA3: Integrated software for Molecular Evolutionary Genetics Analysis and sequence alignment. Brief Bioinform 5, 150-163.

Matsumoto Y, Oda Y, Uryu M, Hayakawa Y (2003) Insect cytokine growth-blocking peptide triggers a termination system of cellular immunity by inducing its binding protein. J Biol Chem 278, 38579-38585.

Miura K, Kamimura M, Aizawa T, Kiuchi M, Hayakawa Y, Mizuguchi M, Kawano K (2002) Solution structure of paralytic peptide of silkworm, Bombyx mori. Peptides 23, 2111-2116.

Miyagawa Y, Kusakabe T, Lee J, Maeda T, Kawaguchi Y, Koga K (2004) Isolation and characterization of differently expressed cDNAs in a meiotic recombination strain of Bombyx mori. Insect Biotechnol Sericology 73, 117-127.

Nakahara Y, Kanamori Y, Kiuchi M, Kamimura M (2003) Effects of silkworm paralytic peptide on in vitro hematopoiesis and plasmatocyte spreading. Arch Insect Biochem Physiol 52, 163-74.

Park HJ, Kim EJ, Koo TY, Park TH (2003) Purification of recombinant $30 \mathrm{~K}$ protein produced in Escherichia coli and its anti-apoptotic effect in mammalian and insect cell systems. Enzyme Microb Technol 33, 466-471.

Ponnuvel KM, Subhasri N, Sirigineedi S, Murthy GN, Vijayaprakash NB (2010) Molecular evolution of the cecropin multigene family in silkworm Bombyx mori. Bioinformation 5, 97-103.

Roach JC, Glusman G, Rowen L, Kaur A, Purcell MK, Smith KD, Hood LE, Aderem A (2005) The evolution of vertebrate Toll-like receptors. Proc Natl Acad Sci USA 102, 9577-82.

Saravanakumar R, Ponnuvel KM, Qadri SMH (2008) Expression of metabolic enzyme genes and heat-shock protein genes during embryonic development in diapause and non-diapause egg of multivoltine silkworm Bombyx mori. Biol 63, 737-744.

Sasagawa H, Nakahara Y, Kiuchi M (2001) An ENF peptide, Bombyx mori paralytic peptide, induces cell proliferation and morphological changes in Bombyx cell lines. In Vitro Cell Dev Biol Anim 37, 638-640.

Strand MR, Hayakawa Y, Clark KD (2000) Plasmatocyte spreading peptide (PSP1) and growth blocking peptide (GBP) are multifunctional homologs. J Insect Physiol 46, 817-824.

Sun Q, Zhao P, Lin Y, Hou Y, Xia QY, Xiang ZH (2007) Analysis of the structure and expression of the $30 \mathrm{~K}$ protein genes in silkworm, Bombyx mori. Insect Sci 14, 5-14.

Ujita M, Katsuno Y, Kawachi I, Ueno Y, Banno Y, Fujii H, Hara A (2005) Glucan-binding activity of silkworm $30-\mathrm{kDa}$ apolipoprotein and its involvement in defense against fungal infection. Biosci Biotechnol Biochem 69, 1178-1185.

Ujita M, Kimura A, Nishino D, Yokoyama E, Banno Y, Fujii H, Hara A (2002) Specific binding of silkworm Bombyx mori $30-\mathrm{kDa}$ lipoproteins to carbohydrates containing glucose. Biosci Biotechnol Biochem 66, 2264-2266.

Walsh JB (1995) How often do duplicated genes evolve new functions? Genetics 139, 421-8.

Wang XY, Cole KD, Law JH (1989) The nucleotide sequence of a microvitellogenin encoding gene from the tobacco hornworm, Manduca sexta. Gene 80, 259-268.

Zhang Y, Dong Z, Liu S, Yang Q, Zhao P, Xia Q (2012) Identification of novel members reveals the structural and functional divergence of lepidopteran-specific Lipoprotein_11 family. Funct Integr Genomics 12, 705-15. Zhong BX, Li JK, Lin JR, Liang JS, Su SK, Xu HS, Yan HY, Zhang PB, Fuji H (2005) Possible effect of $30 \mathrm{~K}$ proteins in embryonic development of silkworm Bombyx mori. Acta Biochim Biophys Sin (Shanghai) 37, 355-361.

Zhu J, Indrasith LS, Yamashita O (1986) Characterization of vitellin, egg-specific protein and $30 \mathrm{kDa}$ protein from Bombyx eggs, and their fates during oogenesis and embryogenesis. Biochim Biophys Acta 882, 427-436. 